\title{
EL EDIFICIO DE TELEFÓNICA EN CÁCERES (1935-1938/39)
}

\section{THE TELEFÓNICA BUILDING IN CÁCERES (1935-1938/39)}

\author{
CRISTIAN HOLGADO ÁVILA \\ Universidad de Extremadura
}

Recibido: 02/05/2019 Aceptado: 21/10/2019

\section{RESUMEN}

Entre 1935 y 1938-1939 la Compañía Telefónica Española construyó una central en Cáceres para instalar los equipos de la nueva red automática de telefonía. Fue diseñada por Paulino Justo Gayo Marín, arquitecto que tuvo gran protagonismo en el desarrollo de este tipo de arquitectura en España. Las centrales telefónicas fueron edificios diseñados con una doble intención: incorporar modernos sistemas de comunicación y proyectar edificios con una estética «propagandística», cuya finalidad era atraer a inversores y accionistas. Este artículo trata de explicar tras un pequeño recorrido histórico y arquitectónico, la creación y las ideas constructivas de la compañía española, para conocer el valor que tiene la obra de Cáceres en el desarrollo urbano de la ciudad.

Palabras clave: Compañía Telefónica Española; central telefónica; Paulino Gusto Gayo Marín; arquitectura; Cáceres.

\section{ABSTRACT}

Between 1935 and 1938-1939 the Spanish Telefónica Company built a telephone exchange in Cáceres to install the equipment of the new automatic telephone network. It was designed by Paulino Justo Gayo Marín, an architect that had a great impact on the development of this kind of architecture in Spain. The telephone exchanges were designed with a double purpose: the first one was to incorporate modern communication sys-tems 
in the cities and the second one was to create buildings with a «propagandistic» aesthetic, with the aim of attracting investors and shareholders. This article tries to explain the creation and the constructive ideas of the Spanish Company, in order to know the value that this building has in Cáceres for the urban evolution of the city.

Keywords: The Spanish Telefónica Company; telephone Exchange; Paulino Justo Gayo Marín; architecture; Cáceres. 


\section{INTRODUCCIÓN}

En la década de los años veinte del pasado siglo, la Compañía Telefónica Nacional de España (en adelante CTNE), desarrolló un hito social y acercamiento a la comunicación en las ciudades más relevantes del país. La CTNE se creó como una filial de la neoyorquina International Telephone and Telegraph (ITT) ${ }^{1}$. Uno de los factores importantes del éxito de la entidad fue el desarrollo de una serie de construcciones para dotar de una red de abastecimiento telefónico, siendo el edificio un factor importantísimo para la garantía de éxito de la empresa $^{2}$.

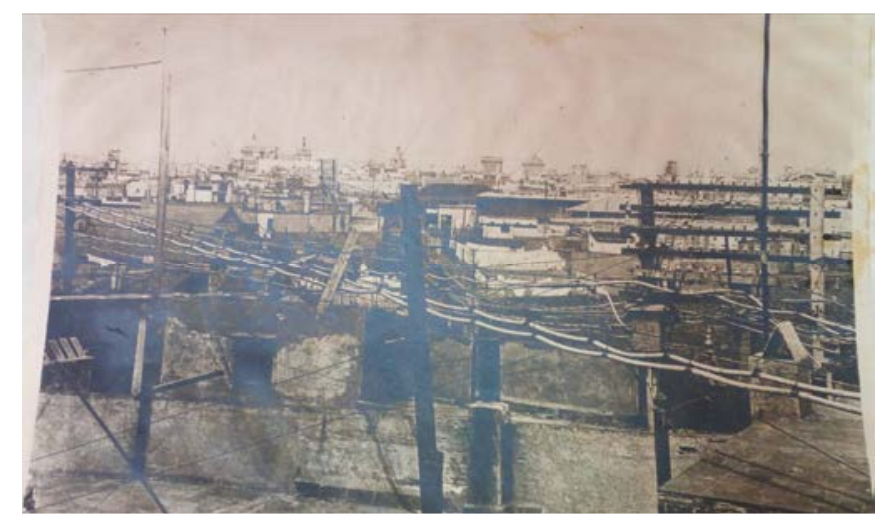

Figura 1. Estado de distribución de una red de cableados y postes, con un aspecto caótico y poco estético (Fotografía: AHMCC).

Sin embargo, en España no existía mucho conocimiento sobre el diseño de centrales, pues los sistemas que existían en las ciudades (fig. 1), según nos muestra una de las memorias justificativas, que emitía la corporación para informar y ofertar el cambio hacia una nueva red de telefonía estaban dotados de:

“... Un sistema de distribución por medio de hilos y cables sobre los tejados, inadecuados para las actuales exigencias del servicio telefónico, ya que dar a los cables principales la capacidad necesaria para servir a los abonados, precisarían ser aquellos de unas dimensiones y peso tales que producirian en los

1 García AlgarRA, F. J., De Gran Vía al Distrito C. El patrimonio arquitectónico de Telefónica, España, Universidad Nacional de Educación a distancia, Tesis Doctoral, 2012, p. 27. Véase: Bagwell, O.C., Parsons, J.J (1945), Navascués, P., Fernández, Á. L (1984), Pilato Iranzo, A (2003), Yuste, A (2004), Calvo, Á (2010), Hernández Muñoz, F. J (2015).

2 DE CÁRDENAS PASTOR, I., "El departamento de Edificios. Notas de su variada y acertada actuación”, Revista telefónica Española, Año 3, Vol. 3, nº 8, 1927, p 12. 
apoyos de los tejados sobrecargas excesivas. Además presenta este sistema los siguientes inconvenientes.

$1^{\circ}$ - Los cables e hilos son inaccesibles y no se puede ejercer la inspección necesaria.

$2^{\circ}$ - Al cruzar plazas de grandes dimensiones resultan los vanos de longitud excesiva, lo que ocasiona a veces la cristalización de la cubierta de plomo, a causa de las vibraciones.

$3^{\circ}$ - Los cables e hilos sobre los tejados están expuestos a los daños ocasionados por tormentas, nieves y etc., como ya ha ocurrido en Barcelona en Noviembre de 1919 y marzo de 1923 y posteriormente en 1925 en Bruselas y Amberes.

$4^{\circ}$ - Las vibraciones de los soportes e hilos, además de ser una molestia para los vecinos son una causa de desperfectos en los edificios.

$5^{\circ}$ - La instalación en los tejados es causas de muchas averías que no solamente produce deficiencias en el servicio sino que también ocasiona perturbaciones, molestias y desperfectos al ser reparadas.

$6^{\circ}$ - Al andar los operarios sobre los tejados para la reparación de las líneas o tendido de otras nuevas, particularmente en el caos de tejados viejos, suelen romperse o removerse tejas, y al quedar sueltas pueden caer ocasionando un peligro para los transeúntes.

$7^{\circ}$ - La necesidad de solicitar permisos de los propietarios o porteros para subir a los tejados originan demoras en la reparación en de las averías.

$8^{\circ}$ - El trabajo de los obreros telefónicos sobre los tejados es peligroso.

Por estas razones, en los modernos procedimientos de construcción, se excluye totalmente la colocación de hilos desnudos y cables sobre tejado..."

Este documento anterior demuestra las innovaciones técnicas que la industria había desarrollado y los nuevos materiales que el sistema de centralización

3 Documento conservado en el Archivo Histórico Municipal de Cáceres (AHMCC). En concreto, se trata de una oferta de la International Telephone and Telegraph Corporation para la reorganización de una red telefónica. Instrucción y cultura 1919-1929, caja 20/459, expte. 28/1923. Asuntos servicios y urbanismo, cultura. Circular con fecha 7 de mayo de 1923, anterior a la adquisición de la red Telefónica Española firmada por el Vicepresidente Lewis J. Proctor. Este documento original es de gran interés, pues muestra la estrategia comercial que utilizaban desde la corporación para la petición de apoyos y conformidad para la creación de la CNTE en el estado español. Vease: PÉREZ YUSTE, Antonio.: La Compañía Telefónica de España en la Dictadura de Primo de Rivera (19241930), Universidad Politécnica de Madrid, Tesis Doctoral, 2004. Capítulo de introducción, pp. 73-83. 
requería (equipos de conmutación, baterías, generadores, rectificadores, etc.) ${ }^{4}$. Para ello, era necesaria una construcción que soportara el empaque propio de una infraestructura adecuada y, en consecuencia, que mejorara el aspecto adverso y de mal gusto que transmitía la presencia de inmensas nubes de cableados y molestos postes, los cuales dañaban la estética urbana, además de dificultar el tránsito de las personas y del tráfico rodado.

Una vez tratada la parte técnica como primer elemento importante que las grandes empresas de telefonía intentaban solventar para mejorar la oferta y así obtener una buena imagen, el otro elemento relevante era el aspecto estético que buscaban estas nuevas entidades para crear una «arquitectura propagandística» que las representara.

A finales de siglo XIX en América, se comenzaron a diseñar edificios con fines publicitarios, principalmente para empresas de negocios, aseguradoras, entidades bancarias y financieras, como un referente atractivo y de dominio de la esfera mercantil ${ }^{5}$, que tuvieran reflejo en las empresas de comunicación. La sociedad debía ser persuadida por obras estéticamente bellas y funcionales, pues fuera de una idea fabril interna, no podía haber también una idea exterior de industria.

Esta maniobra de imagen y marketing se estableció también en el seno de la CTNE. Si bien, se creó un departamento de edificaciones bajo la dirección de Aldrich Durant, con arquitectos contratados para formar una plantilla, con la idea de organizar uno de esos estudios de proyectos modernos y novedosos.

De todos los arquitectos que pasaron por el gabinete de edificación, el más importante en los primeros años de la compañía fue Ignacio de Cárdenas Pastor (1898-1979, titulado. 1924). Trabajó como arquitecto jefe del departamento, y es quien realizó el proyecto de telefónica de la capital madrileña, tras haber pasado una temporada en EE.UU. con Louis S. Weeks. Otro arquitecto importante fue José María de la Vega Samper (1900-1980, titulado. 1924), su segundo y sucesor tras la Guerra Civil. Menos conocidos fueron Luis Clavero Margatí (1899-1970), Paulino Justo Gayo Marín, que llegó a ser el número dos, a partir del exilio de Ignacio de Cárdenas, y tras el posterior nombramiento como director del departamento de edificación José María de la Vega ${ }^{6}$. Todos estos

4 GARCÍA ALGARRA, F. J., “Arquitectura telefónica clásica, el edificio industrial anuncio”, Cuaderno de notas, ETSAM, n' 17, 2016, p. 51.

5 Ibidem., pp. 52-53.

6 GARCÍA ALGARRA, F. J., "Crisis y renovación. Arquitectura de la CTNE en la transición de la Autarquía al desarrollismo", en VI Congreso para la Defensa del Patrimonio Industrial y la Obra Pública en España, TICCIH. El patrimonio industrial en el contexto histórico del franquismo 1939- 
nombres mencionados anteriormente a excepción de Luis Clavero, aparecen como firmantes del proyecto de la ciudad de Cáceres o como directores facultativos de la obra.

\section{APUNTES ESTÉTICOS PARA LAS CENTRALES DE LA CTNE}

Una limitación técnica ${ }^{7}$ de las centrales impedía llevarlas al extrarradio como sería lo más habitual. Las zonas industriales siempre las concebimos en las inmediaciones de las ciudades, como medida de prevención contaminante y de funcionalidad, para operar en espacios más amplios y sin restricciones. Por el contrario, la distancia máxima de la central al domicilio de los clientes no podía estar más alejada de un rango máximo de 3 a 5 kilómetros ${ }^{8}$. Dadas estas circunstancias, se comenzaron a construir edificios funcionales y clásicos, respetando el carácter del entorno, en búsqueda de las zonas con más vida social y más cercanos a los espacios comerciales de las ciudades, para establecer una simbiosis entre la Compañía y la sociedad.

En cuanto a las corrientes conservadoras de la época, el historicismo, eclecticismo y los nacionalismos constituían la estética predominante de la arquitectura en Europa a finales de siglo XIX. A pesar de ello, en aquellos momentos la arquitectura no preocupaba como componente de modernidad para la promoción de las compañías de teléfono, ya que se aceptaban las construcciones seguras y racionales que disponían los departamentos de Correos y Telégrafos para albergar las primeras centrales telefónicas de las ciudades 9 .

1975. Territorios, arquitecturas, obras públicas, empresas, sindicatos y vida obrera. Gijón, Ed. CICEES, 2015, p.644.

7 Se refiere a aspectos concretos de la topología de la red y al problema que causó el aumento de la clientela. El sistema telefónico requerió el empleo cada vez mayor de cableado, el uso de múltiples postes, soportes, conmutadores, baterias en cada casa del cliente, etc., lo que dificultaba su desarrollo hasta que llegó a ser un método ineficaz y superado. Por ello, se optó con las mejoras tecnológicas, por el soterramiento de los sisitemas y la multiplicación de las centrales, dada la complejidad de la estructura necesaria que se necesitaba para soportar la comuniciación de todos los operadores. La mejor opción fue la construcción sólida de un edificio en el centro de las ciudades y establecer una estación central, para que pasaran los hilos exteriores y cables hacia el interior, y conectar con los conmutadores en red y las baterias eléctricas. Así se dió paso en el siglo XX al soterramiento de las líneas, para descongestinar los cielos de las ciudades, llenos de cableados antiestéticos y causantes de muchos problemas, además que se entiendió como un mecanismo de abaratamiento de costes, por el empleo cada vez menor de cableado y soportes, dado que no era neceario recorrer las largas distancias que suponía el modelo de explotación de la telefónia primitiva y el telegráfo. Vease García Algarra, F. J., "De Gran Vía al Distrito C", op.cit., capítulo 2: La mágia cotidiana, ¿Qué es una central?, pp.4774.

8 GARCÍA ALGARRA, F. J., “Arquitectura telefónica clásica”, op. cit., p.49.

9 GARCÍA ALGARRA, F. J., "De Gran Vía al Distrito C”, op.cit., p.188. 
En España será la construcción del edificio de Telefónica de Madrid (19261929), situado en la Gran Vía, y sobre todo a principios del siglo XX en toda Europa, la que marque un antes y un después en la historia de la industria telefónica, ya que se establece definitivamente la proyección de edificios ex profeso como imagen corporativa de la entidad que las patrocina. Esta obra, - que a nivel estético se acerca a las representaciones americanas de palacios telefónicos-, fue proyectada, como ya hemos mencionado, por el arquitecto Ignacio de Cárdenas, con la ayuda del arquitecto neoyorkino, jefe de arquitectura de la International Telephone and Telegraph, Louis S. Weeks. Ésta destaca por su carácter esbelto y su colosal estructura acentuada de inventiva americana, con unos aportes españoles, pues nunca se quiso prescindir de los aspectos castizos, neobarrocos y goticistas que impregnan muchas calles de las ciudades españolas y europeas, como tendencias de los nuevos movimientos estilísticos ${ }^{10}$. Como consecuencia, todos estos recursos fueron necesarios, lo cual explicita que la compañía siempre quiso obtener una imagen que la identificara, para darse a conocer en todo el Estado.

En este sentido, resulta necesario recordar la cita que García Algarra (2012; 299) recoge respecto a la descripción de las primeras construcciones:

“... Los arquitectos tuvieron gran libertad para abordar el diseño formal exterior de los edificios [...] en los inmuebles de la Compañia Telefónica Nacional de España se encuentran todas las tendencias del momento: historicismo, regionalismo, funcionalismo y vanguardia. Ignacio de Cárdenas era capaz de emplear el neobarroco en un rascacielos en Gran Vía y el racionalismo en una pequeña central de León en colaboración con José María de la Vega Samper que, al mismo tiempo, podía diseñar un palacete neoplateresco en el corazón de Salamanca. Santiago Esteban de la Mora y Ramón Aníbal Álvarez, que firmaron algunos de los primeros proyectos del Compañía Telefónica $\mathrm{Na}$ cional de España, pertenecieron al GATEPAC pero su actividad para la Compañia durante los años veinte no se desviaron de la línea más clásica. Debajo de toda esta variedad la primera arquitectura de telefónica escondía unos diseños muy parecidos a los de las centrales americanas...".

En los años siguientes se fueron construyendo en todo el país muchos edificios telefónicos. La idea nacional se completaba con fachadas que estuvieran en armonía con el carácter de cada población: el fomento e imposición del regionalismo a través del promotor como idea principal para erigir los edificios fue la tónica principal hasta bien entrados los años primeros de la Autarquía. Esta nueva cita la vemos reflejada también en la tesis doctoral de García Algarra

10 Ibidem., pp.322-325. 
(2012; 311) y en las páginas de la Revista Telefónica Española (1927; 17-18; Navascués y Fernández; 118):

“... Se levantó en Santander la primera central de un marcado estilo montañés, los edificios de Barcelona, Zaragoza y Bilbao son sobrios, clásicos y fuertes. Alegres y luminosos, el de Valencia y la sucursal de El Graso. En el de Sevilla se empleará toda la riqueza decorativa del arte antiguo y moderno sevillano. En Las Arenas, en Vizcaya, haremos una Central que se asemejará a un pintoresco caserio vasco, y el de la Gran Vía de Madrid, importante, fuerte, majestuoso y muy español y madrileño, edificio que será el cerebro y el corazón de la vasta organización en que trabajamos...".

\section{LA CENTRAL TELEFÓNICA DE CÁCERES (1935-1938-39)}

En este apartado trataremos el proyecto, construcción y en menor medida, la historia del edificio, dado que no hemos podido contar con mucha información. Se trata de la parte más relevante de este trabajo, ya que este edificio apenas ha sido tratado en la bibliografía arquitectónica de Cáceres.

Así como en tantas otras ciudades españolas, la CNTE proyectó la construcción de una sede automática en Cáceres, que se levantó en el solar $\mathrm{n}^{\mathrm{o}} 3$ provisional, de la que entonces se llamaba calle Barcelona (actual Gran Vía). Siguiente a la fachada noroeste del consistorio, el edificio se situó dentro del contexto urbano de la ciudad más relevante, ya que este lugar pasaría a ser la apertura definitiva desde la ciudad antigua hacia la ciudad moderna.

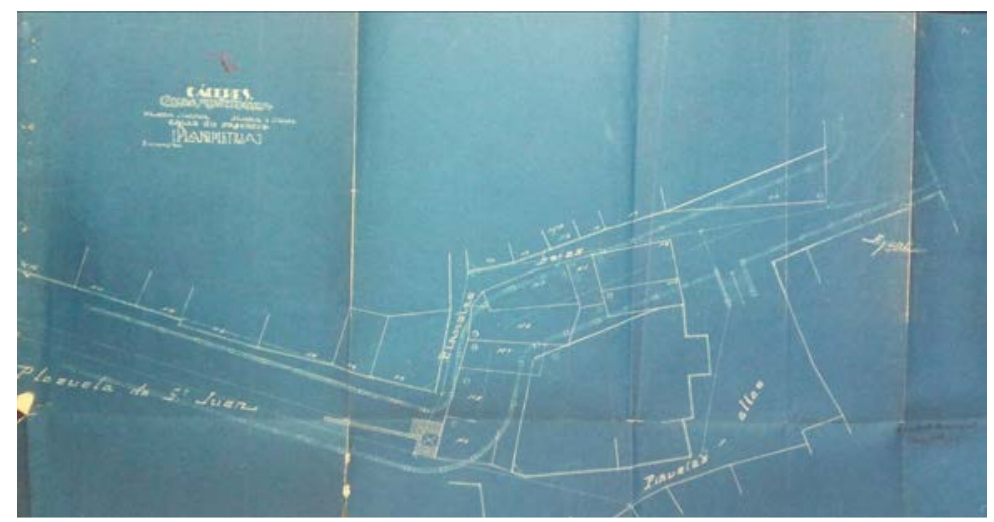

Figura 2. Plano de desarrollo del proyecto de calle de Plaza Mayor y Plaza San Juan. Numeración de cada solar (Imagen: AHMCC). 
Para que se pudiera llevar a cabo la reforma y ensanche de la vía, se tuvieron que realizar expropiaciones de los diferentes terrenos colindantes de la zona, entre la Plazuela de San Juan y la propia calle de Piñuelas Alta y Baja (fig. 2). La superficie utilizada para levantar el edificio fue la que ocupaban las casas $\mathbf{n}^{\mathbf{0}}$ 2 y 4 de Piñuelas Bajas, pertenecientes a los Herederos de Doña Filomena Martín Fernández y hermanos.

En la documentación consultada, estos solares tenían unas dimensiones de $94,50 \mathrm{~m}^{2}$ el $\mathrm{n}^{\mathrm{o}} 2$ y $69,60 \mathrm{~m}^{2}$ el $\mathrm{n}^{\mathrm{o}} 4$, con una tasación económica de las dos edificaciones de 200.000 pesetas, aunque solo hemos recogido un pago del Ayuntamiento de 20.000 pesetas por los terrenos ${ }^{11}$.

El primer contacto de interés por parte de la compañía con el ayuntamiento para erigir la central en la ciudad, lo encontramos en un documento que nos remite a una Comisión Municipal Permanente de 25 de octubre de 1929, donde se recoge:

“... El Alcalde propietario para completar el ensanche de la vía, habia hecho
gestiones particulares con el jefe de teléfonos en esta ciudad, basado sobre la

11 AHMCC. Obras y Servicios, S. XX, caja 20/83, expte. 107(30)/1932. Proyecto de calle desde la Plaza Mayor a San Juan. Vease.: VV.AA “Cáceres. La ciudad en sus planos”, en Cartografia y Paisaje Urbano de Cáceres, Jiménez Berrocal, Fernando (coord.), Cáceres, Concejalía de Cultura, Ayuntamiento de Cáceres, 2012. (Catálogo de exposición). pp. 90-91; CAMPESINO FERNÁNDEZ, Antonio.: Estructura y paisaje urbano de Cáceres, Cáceres, Colegio de Arquitectos de Extremadura, 1982. p. 302. “... La obsesión de las ciudades españolas de esta época por una Gran Vía no es ajena a Cáceres donde es preciso rechazar cualquier snobismo ante la imperiosa necesidad de comunicar la Plaza Mayor con el ensanche, una vez que se decide cerrar al tráfico la arteria comercial de Alfonso XIII en 1924 (sobre todo por lo difícil y peligroso que es la circulación de carruajes por las condiciones de viabilidad) ...". El proyecto que se planteó consistió en unir la Plazuela de San Juan y la Plaza Mayor a través de las Piñuelas, firmado por Emilio María Rodríguez en 1901 y aprobado por el arquitecto ingeniero jefe de obras de la provincia, Manuel Becerra en marzo de 1902, tras exposición pública del proyecto y demás observaciones y, con un presupuesto de 148.550 pesetas. Este expediente no se resolverá favorablemente hasta el mes de mayo de 1926, después de varias sesiones de la Comisión Municipal Permanente, con un informe precedente de 8 de febrero de 1926 del arquitecto municipal Ángel Pérez y otros dos proyectos de construcción de nuevos pavimentos, acerados y alcantarillado entre 1931-1932, para concluir las obras en 1934-35. Obras y Servicios, S.XX, caja 20/44, expte 16; $21 ; 22,(1902)$. Obras y Servicios, S.XX, caja 20/45, expte. 10/1904. Por último, un documento reciente sin clasificar, de 24 de julio de 1901 muestra que, la realización de esta vía hacía tiempo que se perseguía. En concreto desde 1898 se presentó un estudio del arquitecto municipal Rufino Rodríguez Montano sobre la clase de trabajo y expropiaciones de las casas 1, 3, 5, 7 de Piñuelas Bajas al ayuntamiento,

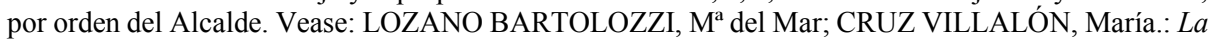
arquitectura en Badajoz y Cáceres: del eclecticismo fin de siglo al racionalismo (1890-1940). Mérida, Ed. Asamblea de Extremadura, 1995, pp 77-78. A partir de 1904-1905 y sobre todo, a partir de la década de los años 30 , con la presentación del proyecto que define la actual artería comentada, es cuando se comenzó con el proceso de expropiaciones según estos documentos consultados. 
cesión de los derechos que el Ayuntamiento tiene a su expropiación a la Compañía Telefónica quien pretende construir local propio ...,"12.

A nivel urbanístico, la denominada «Gran Vía», comienza a ser una realidad a partir del tercer decenio del siglo XX, tras la aprobación de los primeros proyectos para la zona. La obra se alza colindante al ayuntamiento y enfrente, encontramos edificios de viviendas y locales comerciales, propios de la arquitectura popular de la ciudad, de mampostería ordinaria y fábrica de ladrillo, realizados por José María y Luis Morcillo Villar, con un anexo proyectado por el arquitecto municipal Ángel Pérez, de finales de la misma década. Seguidamente, en la misma alineación donde se alzó la central, en un extremo de la misma calle, camino hacia la Plaza de San Juan encontramos el edificio conocido de «Publio Hurtado», con ornamentación ecléctica, de toques modernistas y clasicistas, también de la década en la que se erige la vía, a la espera de quedar culminada con la nueva obra que aquí estamos analizando.

Dentro del contraste de una obra monumental como es la presidida por el ayuntamiento de la ciudad, y lindante a la obra de la familia Hurtado, con una situación privilegiada, haciendo de balcón de entrada hacia lo antiguo a la vez de difícil resolución estructural, es donde debemos contextualizar la obra de telefónica.

El proyecto se presentó el 23 de septiembre de 1935, seguidamente, en la primera semana de noviembre se llega a un acuerdo presupuestado por el material servido por los almacenes municipales, jornales de personal, transporte, dirección y administración. El pliego de planos, memoria, dirección facultativa y demás documentos fueron firmados por el arquitecto Paulino Justo Gayo Marín, el 17 de diciembre de 1935, aunque los planos vienen con fecha de noviembre de 1935, y el aparejador encargado fue Federico de Palomera. Como era habitual, — sin que ello signifique que saliera de su mesa-, algunos planos fueron firmados conjuntamente con Gayo Marín, por el jefe del departamento de construcción Ignacio de Cárdenas. Además, aparece en la realización de una parte del proyecto, la que se refiere a las plantas de cimentación y desagüe, la colaboración del arquitecto, Santiago García Claramunt ${ }^{13}$.

A 30 de diciembre de 1935 la Comisión de Ornato declara que el Excmo. Ayuntamiento debe concederle la licencia solicitada. Pero, en un escrito de la Delegación Oficial del Gobierno, en el Consejo de Administración de la

12 AHMCC. Obras y Servicios, S. XX, caja 20/83., op. cit., Varios escritos; caja 68, borradores de actas Comisión Municipal Permanente año 1929.

13 AHMCC. Obras y Servicios, S. XX, caja 20/95, expte. 51/1935. Nueva red de telefonía en Cáceres, Compañía Telefónica Nacional de España. Memoria y planos expresivos de la obra a ejecutar. 
compañía Telefónica Nacional de España, en oficio del 16 de noviembre de 1935, dice: «la corporación municipal en sesión de 25 de septiembre acordó conceder licencia ${ }^{14}$.

Entre otras cuestiones y como era previsto, antes de la conexión de la red entre el equipo de la central y los aparatos de las personas que contrataban sus servicios, el sistema precisaba primeramente de un tipo de canalización subterránea, que enlazara con la central hacia los principales puntos de cada manzana o viviendas. Iniciado el mes de enero de 1936 se realizan pagos por parte de la Compañía en concepto de obras de soterramiento del tendido de la red, rellenos de zanjas, apisonado del relleno y reconstrucción de pavimentos y obras auxiliares. Los documentos y planos sobre el tendido de la red en la población estuvieron aprobados a fecha de 21 de junio de $1935^{15}$.

Para finalizar con la documentación histórica del edificio, a 1 de abril de 1938, don José María Barbero fue el contratista de la obra invitado por la CNTE al concurso de construcción. Otro documento es el que aparece durante el proceso de edificación, donde la dirección facultativa pasó a fecha de 16 de mayo de 1938, al arquitecto José María de la Vega ${ }^{16}$. La central estaba en activo a 31 de diciembre de 1939, con más de 800 estaciones de telefonía (872 en 1939; 953 en 1940) ${ }^{17}$. Este edificio ha sufrido una reforma de ampliación en el año 1963, que comentaremos posteriormente, realizada por los arquitectos de la compañía que firmaban parte importante de lo que se estaba programando en esa época en todo el país: José María de Anasagasti y Fernando Barandiarán, cuyo resultado fue mantener el carácter del edificio, sin romper la armonía de la obra ${ }^{18}$.

14 Ibidem., memoria descriptiva.

15 Ibidem., memoria descriptiva.

16 AHMCC. Obras y Servicios, S. XX, Caja 108/20, expte, 113/1940. Diligencia firmada por José María de la Vega. Se hace cargo como arquitecto de la dirección de las obras correspondientes al edificio propiedad de la Compañía Telefónica Nacional de España.

17 Compañía Telefónica Nacional de España., "Histórico de informes anuales. Memoria y ejercicio social 1936-1939 y 1940".

[Consulta: 28-04-2019]. https:/www.telefonica.com/documents/153952/13347843/1936_40.pdf

18 AHMCC. Obras y Servicios, S. XX, caja 20/131, expte 309 (49)/1963. instancia de D. Francisco Martin de Nicolás y de Osma, secretario General de la Compañía Telefónica Nacional de España, sobre petición de licencias para ampliar el actual edificio propiedad de dicha compañía en Calle Defensores de Alcazar de Toledo. Además se han localizado varias reformas entre los años 1969, 1970, 1973. Petición de Florentino Rodríguez Martín sobre construcción de tabique y reparación de pintura y enlucido en el local destinado a telefónica, sito en Defensores del Alcazar. Obras y Servicios, S. XX, expte $21 / 1973$. 
En cuanto a su análisis estructural, se trata de un edificio de planta trapezoidal, que constaba originalmente de tres plantas, con una superficie de 554 $\mathrm{m}^{2}$ de superficie construida ${ }^{19}$.

“... Una planta baja, primera y segunda. La planta baja estaba constituida por garaje, carboneras y calefacción, almacén y celadores, pasillos, W.C., escalera, etc. Y un paso cubierto sobre la actual escalinata (fig. 3$)^{20}$. En la planta primera se disponían la sala de público y oficina comercial, servicio interurbano, sala de descanso de señoritas, servicios de W.C. y lavabos para ambos sexos (fig. 4).

En la planta segunda en una gran sala se dispone el equipo telefónico automático con la sala de baterías y servicio de W.C. y lavabo para los mecánicos. La cimentación se hará por macizos de hormigón en masa, la estructura general será de hormigón armado. Los muros de fachada serán de ladrillo macizo y mortero de cemento con decoración de cantería y revoco a la tirolesa.

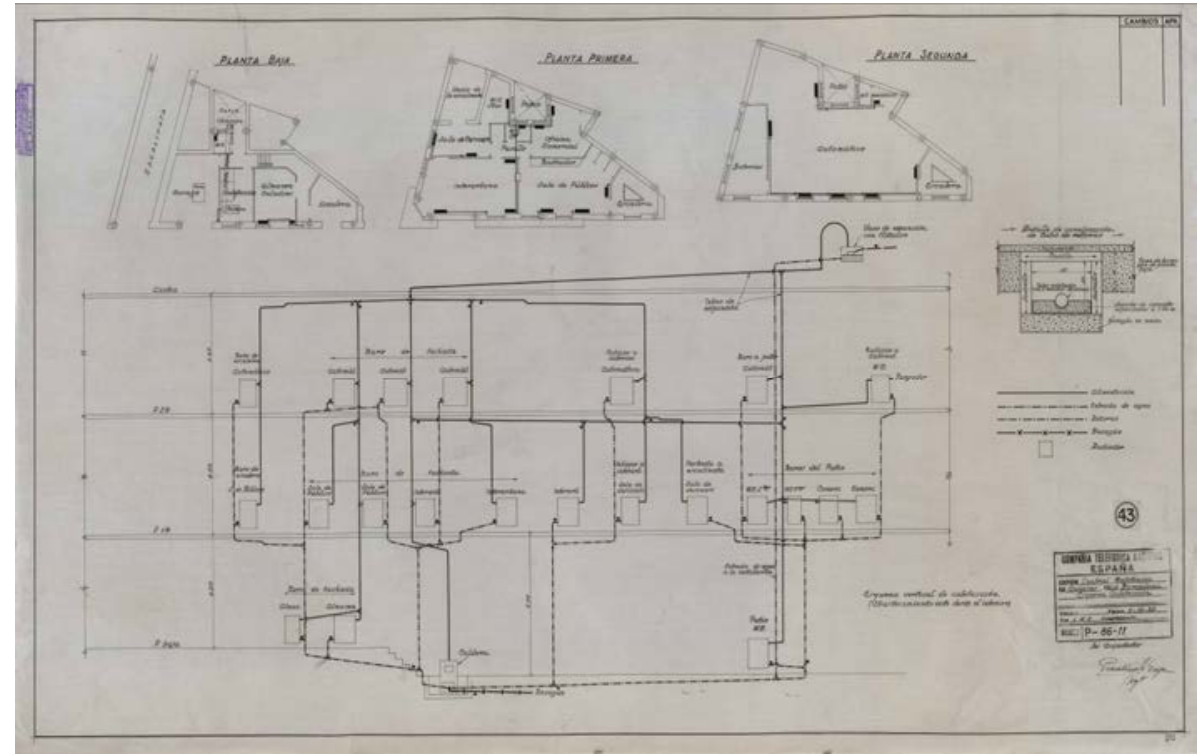

Figura 3. Plano desarrollado del sistema de calefacción de las diferentes plantas (Imagen: Archivo Documental de Telefónica).

19 Sede electrónica del Catastro [Consulta: 30-04-2019]. https://www1.sedecatastro.gob.es/ Cartografia/mapa.aspx?del=10\&mun=900\&refcat=6129502QD2762G0001JG\&final $=$

20 El autor agradece a la Fundación Telefónica por los planos cedidos. Se tratan de las imágenes de la figura $\mathrm{n}^{\circ} 3$ y 6 . 


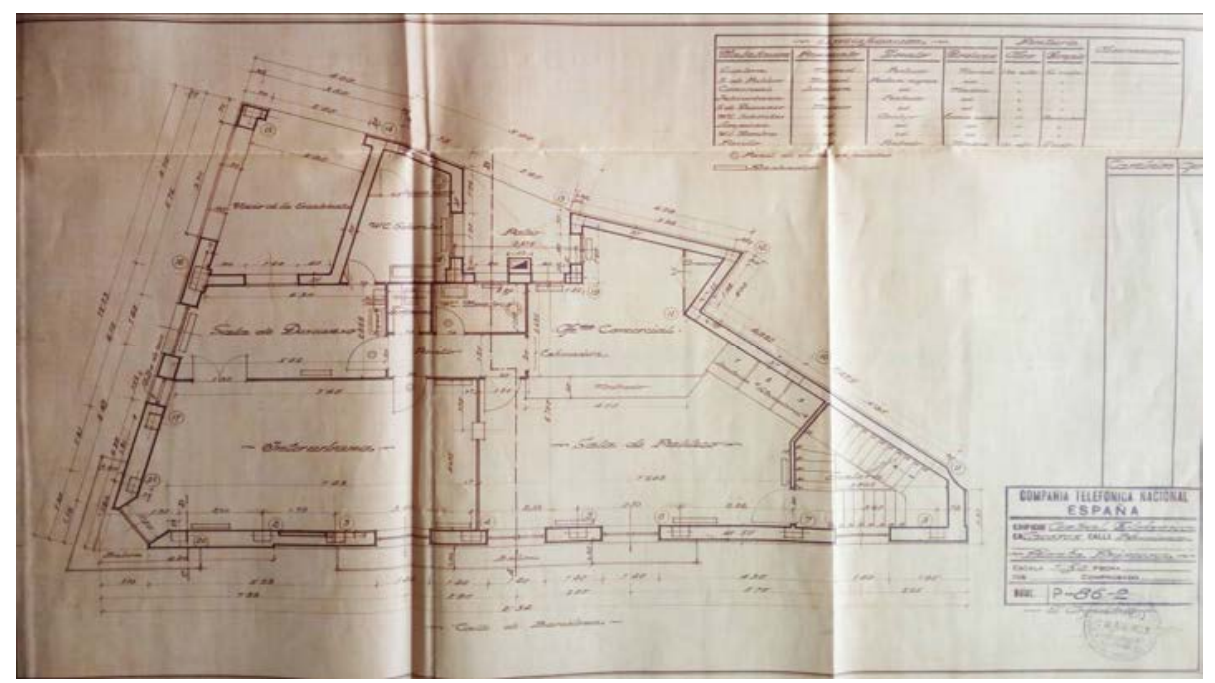

Figura 4 Plano de planta baja (Imagen: AHMCC).

Los restantes muros exteriores e interiores serán de fábrica de ladrillo hueco con mortero de cemento. La cubierta será de formas metálicas con entablado y teja árabe salvo el torreón, (característico de la arquitectura de la CNTE), una pequeña zona destinada a los pósitos de agua que se cubrirán con azotea a la catalana.

Todos los ventanales serán metálicos. La obra se realizará con todo esmero ajustándose a las prácticas de la buena construcción, empleando materiales de inmejorable calidad... ${ }^{21 "}$ (Fig. 5,6).

21 AHMCC. Obras y Servicios, S. XX, caja 20/95., op.cit., memoria descriptiva. 


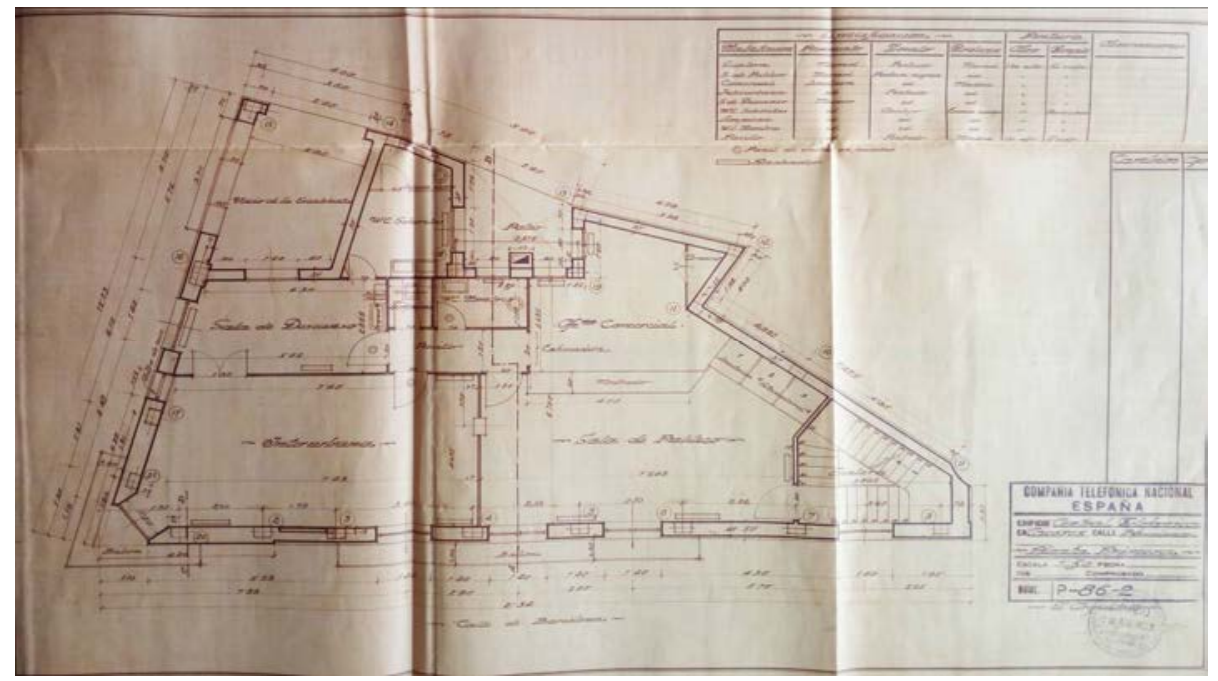

Figura 5. Plano de planta primera (Imagen: AHMCC).

Se deduce de esta memoria la igualdad entre las diferentes alturas diseñadas, el minimalismo compositivo de la fachada y la pesadez de los elementos constructivos, que entran en contraposición con el lenguaje entre lo clásico y lo nuevo. En un esfuerzo de precisión estructural, se observa que las plantas están dispuestas de manera despejada y diáfana sin ningún elemento que moleste el tránsito del público. 

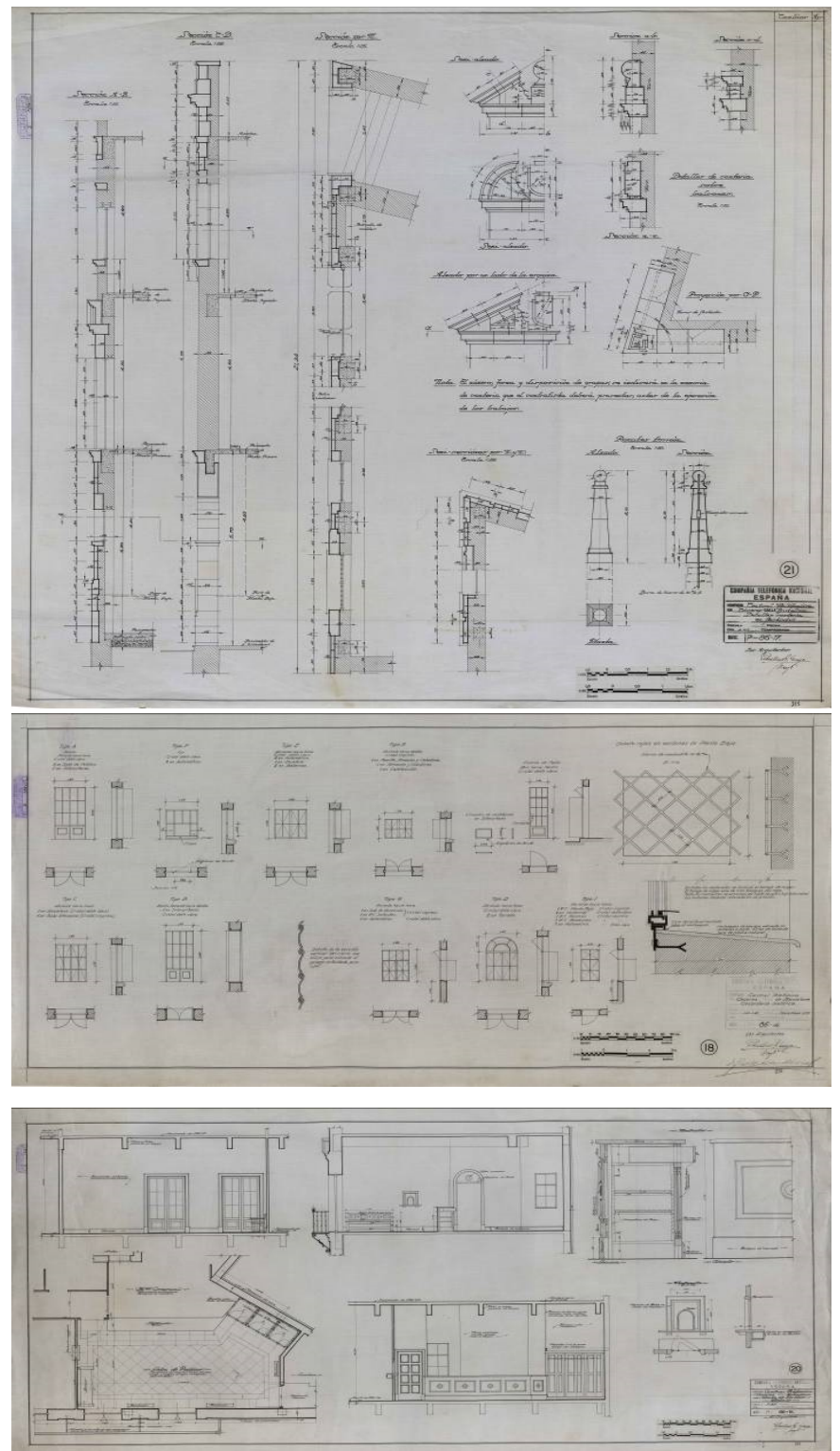

Figura 6. Planos de detalles constructivos (Imagen: Archivo Documental de Telefónica).

El predominio de la funcionalidad y del uso del espacio sin interferencias, se muestran en la primera planta, con las estancias principales (mostradores, 
hall de entrada o sala del público, oficina comercial, interurbana), situadas hacia la fachada principal, relegando las estancias de uso privado a la parte posterior.

La segunda planta estuvo destinada a la zona de automáticos y baterías, siendo un poco más espaciosa, pues fue de uso exclusivo para los operarios técnicos que se encargaban del funcionamiento de la maquinaria de la Compañía.

Para las especificaciones constructivas se optó por los pavimentos de mármol y mosaico, material de lo más lujoso y de gran riqueza, con espacios más sobrios y sencillos en segunda planta, donde se estableció el funcionamiento de la central automática. Los zócalos fueron pintados y con azulejos, al igual que los rodapiés con empleo de mármol, madera y pintura. Finalmente la pintura fue empleada al óleo y temple tanto para la pared de interiores, exteriores y el techo del edificio.

Estéticamente, de las tres fachadas que presenta el edificio, la imagen que se alza hacia la «Gran Vía» es la que mayor profusión ornamental tiene en su tratamiento (fig. 7, 8, 9, 10). Dada su importancia, su distribución se establece horizontalmente, como un friso decorativo que repite sistemáticamente el discurso estilístico en las demás alturas.

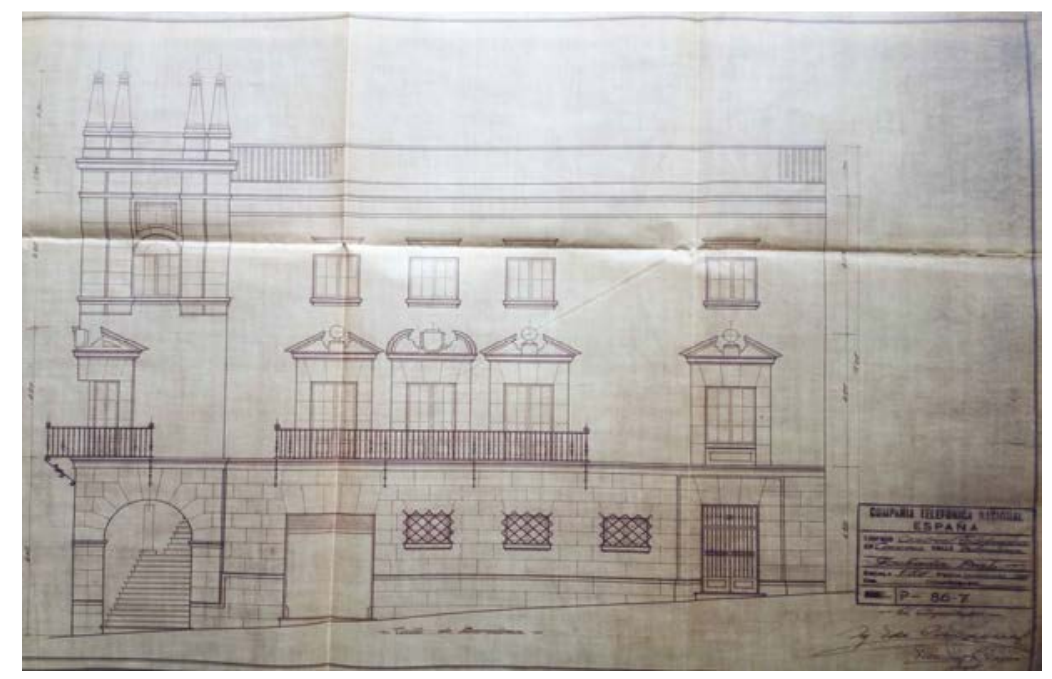

Figura 7. Plano de alzado principal (Imagen: AHMCC). 


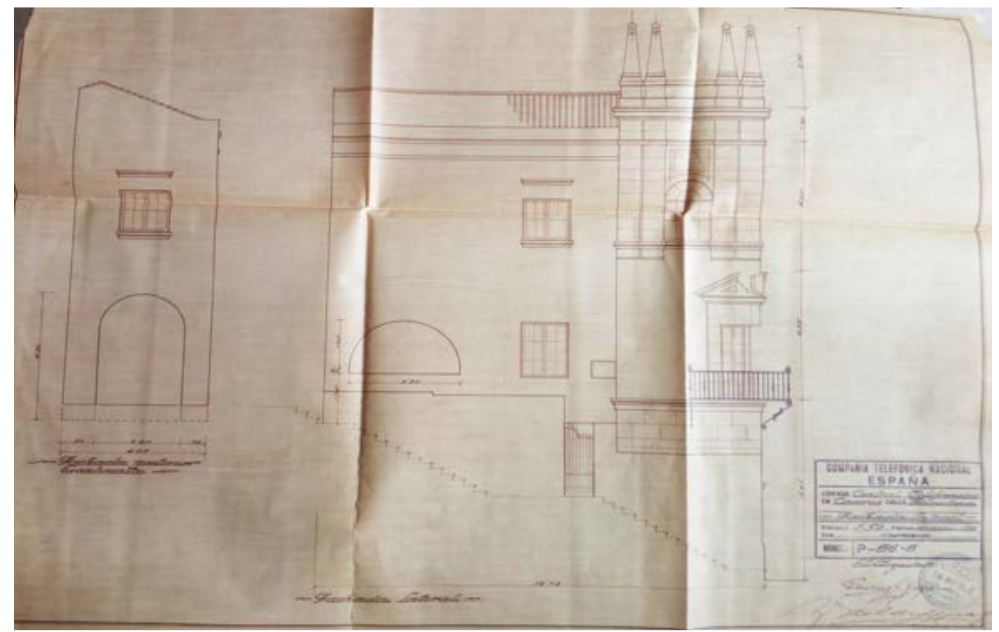

Figura 8. Plano de alzado lateral (Imagen: AHMCC)

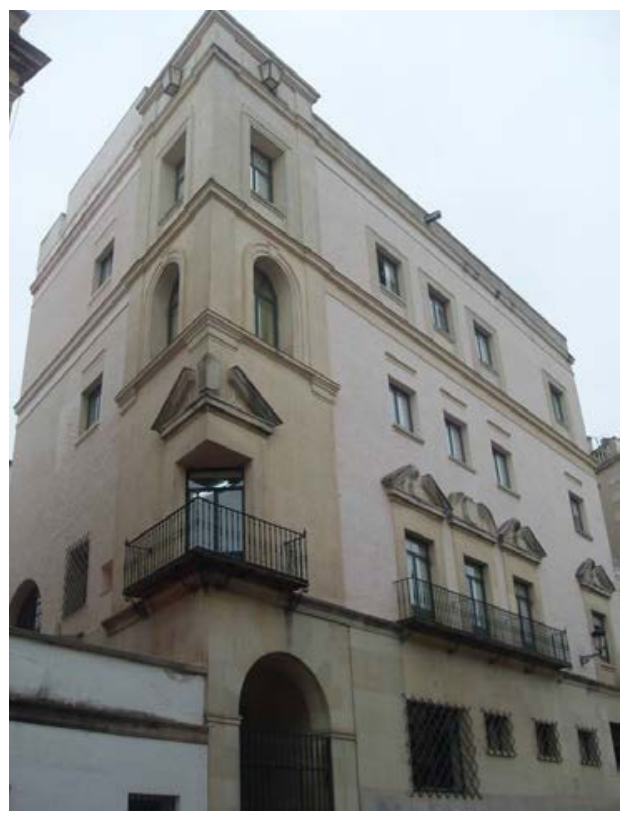

Figura.9 alzado principal hacia la Gran Vía.

La primera planta, queda a nivel de la acera y se compone de un cuerpo formado por un almohadillado corrido, con tres vanos enrejados modernos, entrada principal en un extremo y escalera de acceso hacia la calle de Piñuelas Altas, 
situada en el otro extremo. A modo de basamento sobre el que se asienta la segunda zona o planta resaltan los diferentes ventanales sobre recercado de piedra, rematados en balconada de hierro los tres centrales, para dejar libre las aperturas que conforman el cierre de la fachada restante. Se trata de una serie de miradores coronados por frontones partidos triangulares y semicirculares que se intercalan, con escudos lisos sin blasón en el interior de los frontones, y rematados con bolas al estilo clásico español. De nuevo, un ventanal con gran recercado en el lado derecho, y un balcón de esquina con toques decorativos, son los elementos compositivos que comprenden el conjunto de esta parte del edificio.

Sin diferenciación en el desarrollo de la fachada queda la tercera planta. A nivel estético, según se sube en altura las ventanas disminuyen en expresión y decoración; cuatro ventanas rematadas con un pequeño dintel en la parte superior, y con vierteaguas en la parte inferior, son los únicos elementos estéticos que aparecen en torno a estas. Como en la planta anterior, en el extremo izquierdo del alzado se despliega un torreón realizado con simulación de sillería, igual que la parte de la base de la primera planta, con un balcón de forja decorativa que acusa mayor importancia que en toda la planta por su ornamentación especial. Este torreón está compuesto por un ventanal enmarcado y rematado en arco, rompiendo con el ritmo de los demás enmarques, pues donde había entablados o dinteles horizontales, ahora aparece la curva, recordando una secuencia constructiva, como la que experimentaron el propio Serlio o Palladio.

La cubierta se culminó con unos pináculos en formas de diamantes muy estilizados, que coronaban con rotundidad el edificio según aparece en el proyecto y en la imagen que hemos mostrado. El resto de la fachada va toda enfoscada con cemento y a la tirolesa en tono suave, mientras que las jambas, dinteles, vierteaguas de ventanas, así como cornisas y recercados, son de piedra caliza.

Dada la estrechez estructural del edificio, el alzado hacia la vía principal queda libre y funciona como un telón efectista, que representa el pasado arquitectónico de la ciudad monumental: los frontones partidos del barroco, junto con el balcón de esquina que rememora la arquitectura palatina del siglo de XVI de las ciudades de Cáceres y Trujillo, recuerdan los ejemplos más bellos del entorno. Sin embargo, es de destacar que, a pesar del aspecto histórico exterior del inmueble, su estructura interna muestra una moderna estética que se manifiesta en una simple organización del interior para uso público, transferida hacia la fachada con ventanales pesados pero simplificados. Por lo tanto, lo que se ha conseguido es una limpieza compositiva y un empleo de elementos y materiales constructivos modernos, que reflejan el ideario «nacionalista» de construir que tuvo el gabinete de edificación de la empresa telefónica en sus primeros diseños. 


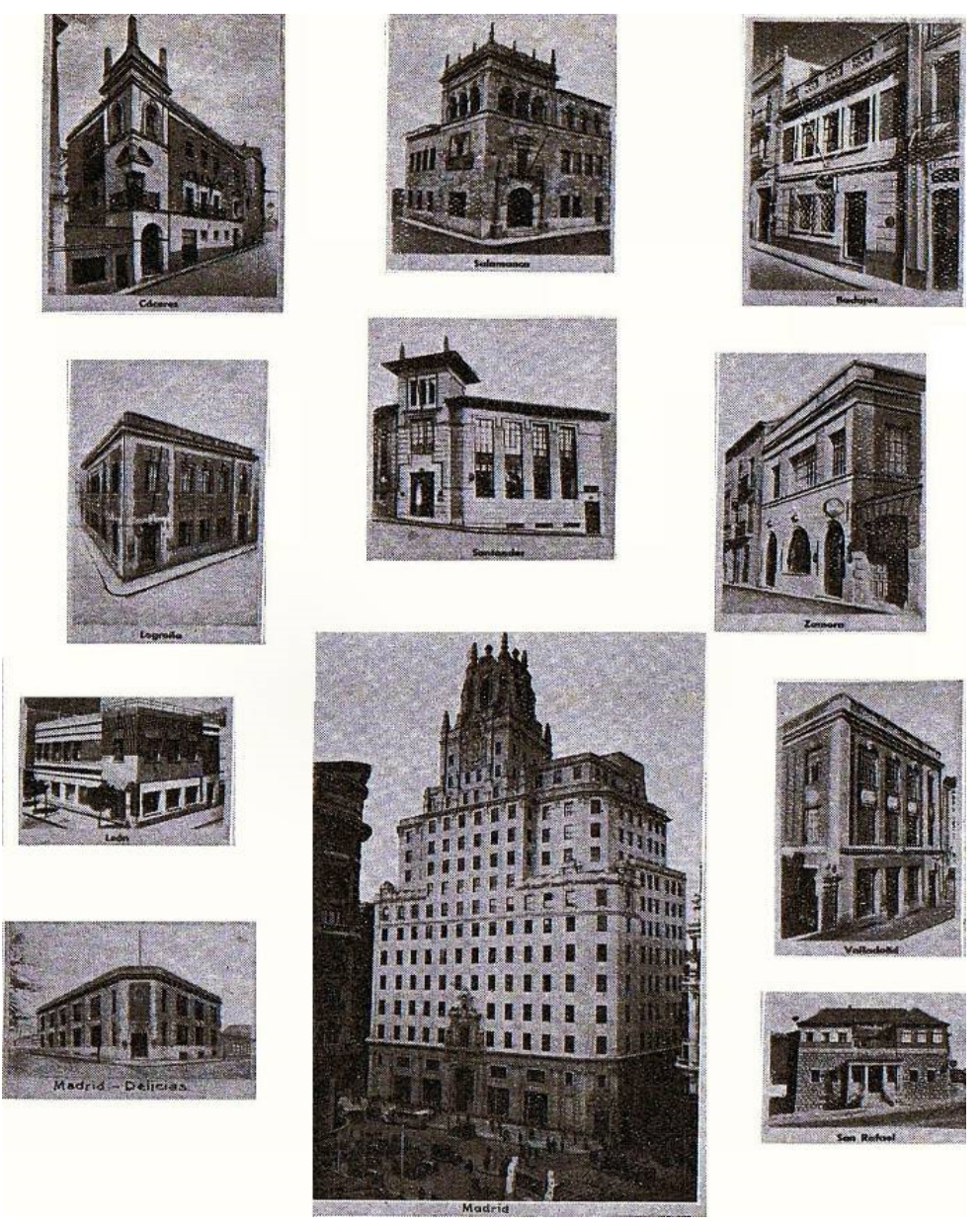

Figura.10 Hueco grabado de diferentes centrales españolas. Arriba a la izquierda se muestra la de Cáceres (Imagen: F.J. García Algarra).

\section{LA REFORMA DEL EDIFICIO DE 1963}

Seguidamente, en 1963 se presenta la ampliación de una planta más en la parte superior del edificio. Con este trabajo se sustituyó la torre esquinada y los pináculos, desapareciendo los elementos decorativos y dejando una planta de cornisa corrida, por el necesario acrecentamiento del espacio de la CNTE. 
La ampliación fue llevada a cabo por los arquitectos madrileños José María de Anasagasti y Fernando Barandiarán, y cuyo aparejador de la obra fue Antonio Pimienta Estévez. El proyecto viene fechado en marzo y mayo de 1963, y la aprobación por parte de la Comisión Municipal es propuesta el 31 de julio del mismo año. En esta reforma se establecieron 4000 líneas nuevas para dotar a la ciudad de la máxima cobertura telefónica dado el incremento demográfico de la época ${ }^{22}$.

La nueva planta mantuvo características análogas a las primeras, en cuanto a la posición de superficies, los huecos de la escalera y de ventilación en las fachadas. La distribución interior no existió prácticamente porque se dedicó exclusivamente a equipos automáticos.

En las fachadas también se procuró mantener el carácter del edificio. El torreón se prolongó en altura, y el empleo del material fue el mismo que el utilizado en todo el conjunto. Únicamente se varió el nuevo hueco que tiene, que en lugar de realizar uno curvo, se optó por establecer un dintel horizontal. Las ventanas están ordenadas simétricas en la fachada. Se desarrollan unos recercados de piedra a juego con los que tienen la primera planta. En general, el poder mantener las cornisas corridas, como entablamentos diferenciadores de cada altura, permiten separar en el conjunto las diferentes capas del edificio, sin romper la coherencia constructiva del mismo.

La estructura es de hormigón armado y en la memoria se recoge que «está calculado de modo que pueda elevarse en su día una nueva planta, que haría la quinta de la central $»^{23}$. Los muros son de fábrica de ladrillo con revoco igual a los que ya existen. El presupuesto que se extrae de los pliegos de condiciones y de las mediciones de esta intervención fue de 956.062,49 ptas.

\section{CONCLUSIONES}

En este trabajo hemos intentado acercar la labor que realizó la CNTE en España, para establecer los equipos telefónicos automáticos y mejorar el servicio en las ciudades. La distribución de las nuevas líneas se hizo a partir de una sede central para repartirlas hasta todos los aparatos de los abonados. Es entonces cuando el desarrollo del programa de construcciones de la CTNE comienza a ser una realidad y diseñan edificios siempre con la doble finalidfad: crear una arquitectura propagandística, proveniente de los modelos de explotación financiera americanos, y como contenedores de las instalaciones de telefonía.

22 AHMCC. Obras y Servicios, S. XX, caja 20/131., op.cit., memoria descriptiva.

23 AHMCC. Obras y Servicios, S. XX, caja 20/131., op.cit., memoria descriptiva. 
A pesar de ello, en España no había mucho conocimiento sobre edificios de este tipo y se tuvo que desarrollar un departamento de edificaciones que organizara, al modo de un estudio de arquitectura moderno, a jóvenes profesionales contratados para adoptar las ideas constructivas principales que salían de las conferencias y publicaciones que los jefes del departamento establecieron como modelos organizativos y de construcción, aplicándolas con éxito en la mayoría de los casos.

La central de Cáceres se proyectó en el marco de toda esta nueva idea de telefonía, como en muchas de las principales ciudades españolas, durante la década de los años treinta. Como hemos podido comprobar a lo largo de nuestra exposición, se trató de construcciones de carácter fabril, con una organización interna espaciosa y diáfana para la incorporación de los aparatos telefónicos. Sin embargo, en su parte exterior apreciamos la estética del entorno, la búsqueda de continuidad estilística y urbana, con mezcla entre lo histórico y lo moderno como tendencia habitual de este periodo, que García Algarra denomina la «época dorada de Telefónica» antes de la Guerra Civil ${ }^{24}$.

\section{BIBLIOGRAFÍA}

BAGWELL, O. C. y PARSONS, J. J., "Veinte años de la telefonía en España", comunicaciones electrónicas, International Telephone and Telegraph Corporation, Vol. 22, no 4, 1945, pp. 321-341.

CALVO, Á., Historia de Telefónica 1924-1975. Primeras décadas: tecnología, economía y política. Madrid, Ariel/Fundación Telefónica, 2010.

CAMPESINO FERNÁNDEZ, A., Estructura y paisaje urbano de Cáceres, Cáceres, Colegio de Arquitectos de Extremadura, 1982.

DE CÁRDENAS PASTOR, I., "El departamento de Edificios. Notas de su variada y acertada actuación”, Revista telefónica Española, Año 3, Vol. 3, nº 8, 1927, pp. 12-21.

GARCÍA ALGARRA, F. J., "Las primeras centrales de Telefónica en Galicia", Boletín Académico, ETSAC, n 2, 2010, pp. 1-8.

-, De Gran Vía al Distrito C. El patrimonio arquitectónico de Telefónica, España, Universidad Nacional de Educación a distancia, Tesis Doctoral, 2012.

- et al., "Los orígenes de la arquitectura telefónica en España: las centrales madrileñas del Grupo Peninsular", Espacio, Tiempo y Forma, UNED, serie VII, Historia del Arte, T. 25, 2012, pp. 275-294.

24 El autor agradece a F.J García Algarra por la cesión de la imagen del hueco grabado, y a Pablo y José Ramón, gestores del blog sobre la historia de telefónica, por sus aportaciones valiosas previas a este trabajo. 
- "Crisis y renovación. Arquitectura de la CTNE en la transición de la Autarquía al desarrollismo", en VI Congreso para la Defensa del Patrimonio Industrial y la Obra Pública en España, TICCIH. El patrimonio industrial en el contexto histórico del franquismo 1939-1975. Territorios, arquitecturas, obras públicas, empresas, sindicatos y vida obrera. Gijón, Ed. CICEES, 2015, pp. 643648.

- "Arquitectura telefónica clásica, el edificio industrial anuncio", Cuaderno de notas, ETSAM, no 17, 2016, pp. 49-62.

HERNÁNDEZ MUÑOZ, F. J., La Arquitectura de Telefónica de España: el edificio de la Gran Via, Universidad de Málaga, Tesis Doctoral, 2015.

LOZANO BARTOLOZZI, Ma del Mar; CRUZ VILLALÓN, María.: La arquitectura en Badajoz y Cáceres: del eclecticismo fin de siglo al racionalismo (1890-1940). Mérida, Ed. Asamblea de Extremadura, 1995.

NAVASCUÉS, P., "El edificio de la Compañía Telefónica Nacional de España en Madrid”. En Navascués, P., Fernández, Á. L (Eds.)., El Edificio de la Telefónica. Madrid, Espasa Calpe, 1984, pp. 107-176.

PILATO IRANZO, A., "Los edificios de la telefónica en valencia (1926-1928)", Ars Longa, no 12, 2003, pp. 101-112.

PÉREZ YUSTE, A., La Compañía Telefónica de España en la Dictadura de Primo de Rivera (1924-1930), Universidad Politécnica de Madrid, Tesis Doctoral, 2004.

—, "La creación de la Compañía Telefónica Nacional de España en la Dictadura de Primo de Rivera", Cuadernos de Historia Contemporánea, Universidad Complutense de Madrid, vol. 29, 2007, pp. 95-117.

VV.AA “Cáceres. La ciudad en sus planos", en Cartografia y Paisaje Urbano de Cáceres, Jiménez Berrocal, Fernando (coord.), Cáceres, Concejalía de Cultura, Ayuntamiento de Cáceres, 2012. (Catálogo de exposición).

Compañía Telefónica Nacional de España., "Histórico informes anuales. Memoria y ejercicio social 1936-39 y 1940". [Consulta:16-01-2019]. https://www.telefonica.com/documents/153952/13347843/1936_40.pdf

Sede electrónica del Catastro, [Consulta:19-01-2019]. https://www1.sedecatastro.gob.es/Cartografia/mapa.aspx?del=10\&mun=900\&refcat=6129502QD27 62G0001JG\&final=

Cristian Holgado Ávila

Departamento de Arte y Ciencias del Territorio

Área de Historia del Arte

Universidad de Extremadura

Av. Universidad, s/n. 10003 Cáceres (España) https://orcid.org/0000-0002-3983-0154 cristianholgadoavila@gmail.com 